\title{
Group Transfer from Silicon to Carbon via Tandem Radical Cyclizations of Acylsilanes
}

\author{
Yeun-Min Tsai,* Kuo-Hsiang Tang and Weir-Torn Jiaang \\ Department of Chemistry, National Taiwan University, Taipei 106, Taiwan, Republic of China
}

\begin{abstract}
Tandem radical cyclizations of acylsilanes with alkene or alkyne functionalities attached to silicon afforded cyclic silyl ethers which were oxidatively hydrolyzed to give diols or ketone alcohols. Copyright (C) 1996 Elsevier Science Ltd
\end{abstract}

Acylsilane is an useful functional group which has gained more and more attentions. I Recently, we reported radical cyclizations of acylsilanes 1 (scheme I). 2a The key step of this process involves a radical Brook rearrangement 2,3 of the initially formed $\beta$-silyl alkoxy radicals 2 to give silyloxy substituted radicals 3 .

Hydrogen atom abstraction of $\mathbf{3}$ then affords cycloalkyl silyl ethers 4 . However, with suitable design, radicals of the type 3 can be employed to construct carbon-carbon bond through intermolecular processes ${ }^{2 \mathrm{~b}}$ or intramolecular tandem cyclizations. ${ }^{2 c}$ In this communication, we report the intramolecular transfer of substituent from silicon to carbon through tandem radical cyclizations.

\section{Scheme I}
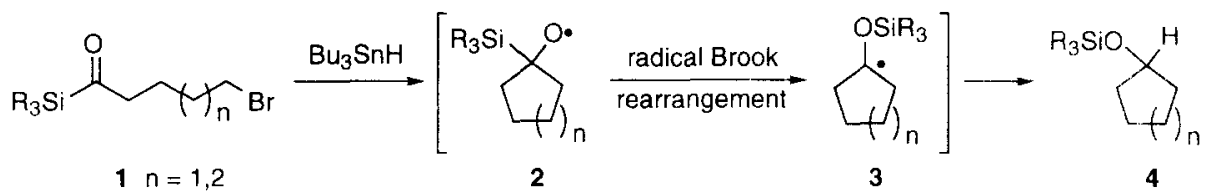

As shown in scheme II, silylation of 1,3-dithiane with allylchlorodimethylsilane or (3-butenyl)chlorodimethylsilane gave the corresponding 2-silyl-1,3-dithianes $\mathbf{5 a}(83 \%)$ and $\mathbf{5 b}(64 \%)$. Alkylation of $\mathbf{5 a}$ or $\mathbf{5 b}$ with 1,4-dibromobutane or 1,5-dibromopentane followed by hydrolysis of the dithiane moiety with ceric ammonium nitrate (CAN) ${ }^{4}$ or iodobenzene bis(trifluoroacetate $)^{5}$ gave bromo acylsilanes $6 \mathbf{a}-6 \mathbf{d}$ in mild yields.

When 6a was treated with tributyltin hydride in refluxing benzene (scheme III), a mixture of 7a-9a was obtained. Since these silyl ethers were volatile and difficult to isolate, we directly treated the crude product mixture under Tamao oxidation condition ${ }^{6}$ to afford diols $10 \mathbf{a}(21 \%)$ and $11 \mathbf{a}^{7}(40 \%)$. The isolation of $10 \mathrm{a}$ indicated the formation of $\mathbf{8 a}$ in the radical cyclization step. The origin of 11a should be the spiral silyl ether 9a. Analysis of the crude cyclization mixture by $\mathrm{GC}^{8}$ showed three peaks with a ratio of 1:3:9. Coinjection of authentic $7 \mathbf{a}$ indicated that this monocyclic product was the minor component. Since silyl ether $7 \mathbf{a}$ was only present in small quantity, we were not able to isolate the corresponding cyclopentanol after the oxidative hydrolysis step. From the relative amounts of the diols isolated, we believed that silyl ether 9 a should correspond to the major component observed in our GC analysis. 


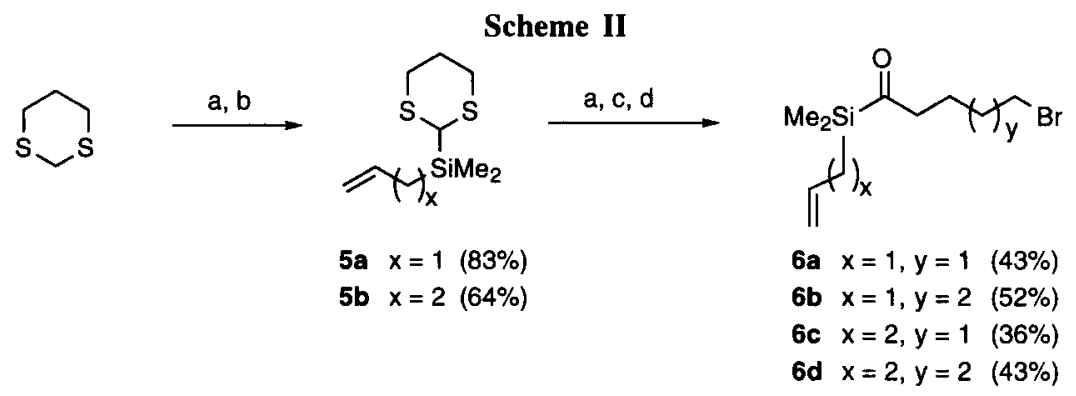

Reagents and conditions: (a) BuLi, THF, $-78^{\circ} \mathrm{C}$; (b) $\mathrm{CH}_{2}=\mathrm{CHCH}_{2} \mathrm{SiMe}_{2} \mathrm{Cl}$ or $\mathrm{CH}_{2}=\mathrm{CH}\left(\mathrm{CH}_{2}\right)_{2} \mathrm{SiMe}_{2} \mathrm{Cl}$; (c) $\mathrm{Br}\left(\mathrm{CH}_{2}\right)_{4} \mathrm{Br}$ (2 equiv) or $\mathrm{Br}\left(\mathrm{CH}_{2}\right)_{5} \mathrm{Br}$ (2 equiv), $-20^{\circ} \mathrm{C}$; (d) $\mathrm{CAN}$ (4.1 equiv), $\mathrm{MeOH}, \mathrm{CH}_{2} \mathrm{Cl}_{2}$ for $6 \mathrm{a}$; $\left(\mathrm{CF}_{3} \mathrm{COO}\right)_{2} \mathrm{IPh}$ (1.7 equiv), $\mathrm{NaHCO}_{3}$ (7 equiv), $\mathrm{CH}_{3} \mathrm{CN}, \mathrm{H}_{2} \mathrm{O},-20^{\circ} \mathrm{C}$ for $6 \mathrm{~b}-6 \mathrm{~d}$.

Mechanistically, the cyclization involved the generation of radical 12a which cyclized to give alkoxy radical 13a. Radical Brook rearrangement ${ }^{2,3}$ of 13a afforded 14a. Direct hydrogen atom abstraction of 14a from tributyltin hydride gave 7a. 5-Exo-trig and 6-endo-trig cyclization of $14 \mathbf{a}$ led to $8 \mathbf{a}$ and $9 \mathbf{a}$, respectively. It is well-known that $\gamma$-silicon substituted radical undergoes 6-endo-trig cyclization preferentially. ${ }^{9 \mathrm{a}-9 \mathrm{c}}$ Our results are in coherence with this trend.

Radical cyclization of $6 \mathrm{~b}$ followed by oxidative hydrolysis gave $25 \%$ of $10 \mathrm{~b}$ and $55 \%$ of $11 \mathrm{~b}$. Again, the endo-cyclization product prevailed. Analysis by $\mathrm{GC}^{8}$ showed the presence of four peaks with ratio of 1:5:13:1 corresponding to $\mathbf{7 b}, \mathbf{8 b}, 9 \mathbf{b}$, and $\mathbf{1 5}$, respectively. The presence of the uncyclized product 15 was confirmed by coinjection of an authentic sample. ${ }^{10}$ Homoallyl substituted silanes $\mathbf{6 c}$ and $\mathbf{6 d}$ cyclized in much better regioselectivity in favor of 7-endo-trig over 6-exo-trig. ${ }^{9 \mathrm{~d}}$ From $6 \mathrm{c}$, we isolated diol 16a (67\%) and $17 \mathbf{a}(3 \%)$ after oxidative hydrolysis. Analysis of the crude cyclization mixture by $\mathrm{GC}^{8}$ showed $18 \mathbf{a}: 19 \mathbf{a}: 20 \mathrm{a}=4: 24: 1$. Similarly, Diol 16b was obtained from 6d in $79 \%$ yield. We did not observe the presence of $20 \mathrm{~b}$ by GC. However, monocyclic $\mathbf{1 8 b}$ and uncyclized 21 were present in $10 \%$ and $9 \%$, respectively, by GC analysis. ${ }^{8}$

This methodology also worked nicely in a triple cyclization cascade. Dithiane 23 prepared from alkyne 22 (47\%) was converted to acylsilane $24(65 \%)$ as shown in scheme IV. Radical cyclization of 24 with tributyltin hydride in refluxing benzene gave two isomeric tricyclic products $25 \mathbf{a}(24 \%)$ and $\mathbf{2 5} \mathbf{b}(8 \%)$. Treatment of $25 \mathbf{a}$ and $\mathbf{2 5 b}$ independently under oxidative hydrolysis condition afforded the same ketone diol 27 in $60 \%$ and $56 \%$

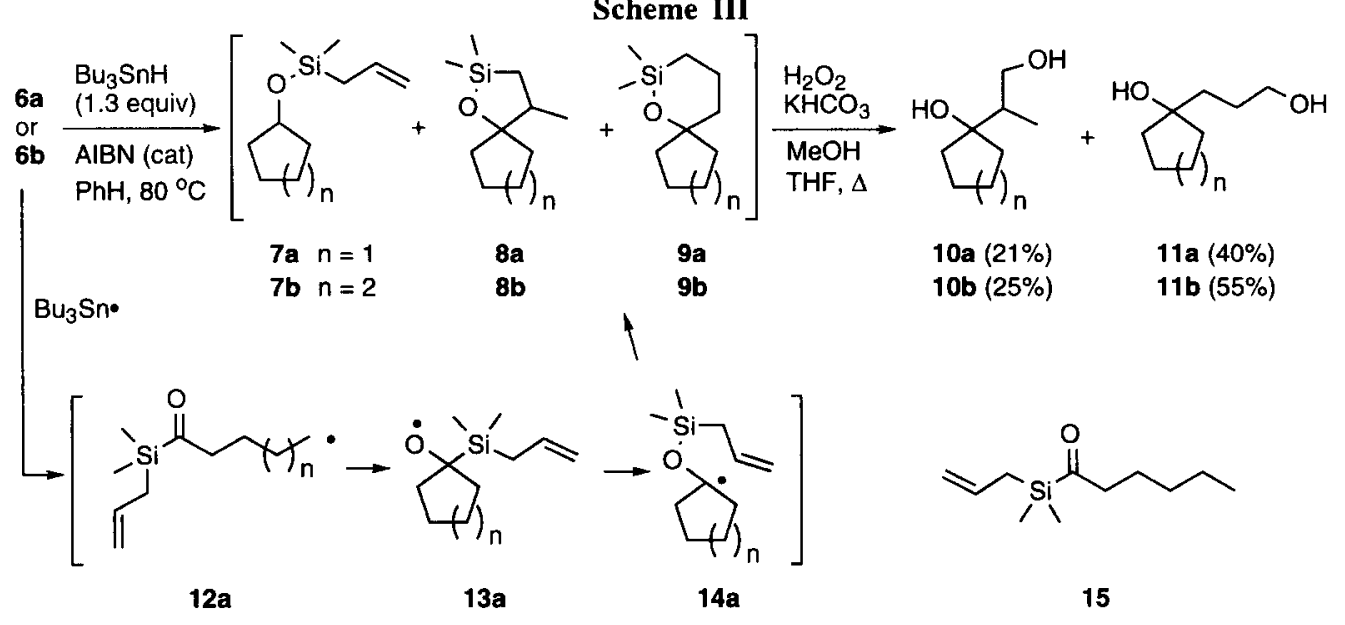


<smiles>OCCCCC1(O)CC2CCCC2C1</smiles>

16a $n=1$

16b $n=2$<smiles>C[Si]1(C)CCCCC2(CCCC2)O1</smiles>

$19 a$

19b<smiles>CC(CCO)C1(O)CCCCC1</smiles>

$17 a$

$17 b$<smiles>CC1CC[Si](C)(C)OC12CCCCC2</smiles>

20a

$20 \mathrm{~b}$<smiles>C=CCC[Si](C)(C)OC1CCCC1</smiles><smiles>C=CCC[Si](C)(C)C(=O)CCCCC</smiles>

21

yield, respectively. These experiments confirmed that $\mathbf{2 5 a}$ and $\mathbf{2 5 b}$ were $Z, E$ isomers in respect to the carboncarbon double bond. ${ }^{11}$ In addition to the tricyclic products, we have also isolated $5 \%$ of a desilylated bicyclic alcohol $26^{12}$ and $23 \%$ of uncyclized straight reduction product. The relative stereochemistry of the indane nucleus in 25 was assigned based on our previous results ${ }^{3 \mathrm{~d}}$ and other similar systems ${ }^{12,14}$ that the first two cyclizations preferred to give radical 28. Furthermore, ${ }^{13} \mathrm{C}$ NMR of $26^{13}$ showed that $\mathrm{C}_{3 \mathrm{a}}$ appeared at $\delta 81.0$. While in the endo-methyl isomer of $26,{ }^{12 b} \mathrm{C}_{3 \mathrm{a}}$ appeared at $\delta 78.2$. Compared with these values, $\mathrm{C}_{3 \mathrm{a}}$ of 27 appeared at $\delta 77.2$. This number correlates well with the endo-isomer of $\mathbf{2 6}$.

When the cyclization reaction of $\mathbf{2 4}$ with tributyltin hydride was performed at room temperature using triethylborane-air for initiation, ${ }^{15}$ much better yields of $25 \mathbf{a}(42 \%)$ and $25 \mathbf{b}(9 \%)$ were obtained. It was noted that the cyclization of $\mathbf{2 8}$ provided a rare example of $\varepsilon$-silicon substituted radical cyclized in a 6-exo-dig fashion.

In summary, radical cyclizations of acylsilanes with alkene or alkyne functionalities attached on silicon

Scheme IV<smiles>C#CC(C)(C)[OH+]</smiles>

22<smiles>CC(C)(O)/C=C/C[C@H]1CCC2CCCCC21O[Si](C)(C)C</smiles>

$25 a+25 b$<smiles>CC1CCC2CCCCC12O</smiles>

26<smiles>C=CCCC(Br)CCCCC(=O)[Si](C)(C)C#CC(C)(C)O</smiles>

23<smiles>CC(C)(O)CC(=O)C[C@H]1CCC2CCCCC21O</smiles>

27<smiles>C[C@H]1CCCC[C@@]1(C)O[Si](C)(C)C#CC(C)(C)O</smiles>

28

Reagents and conditions: (a) BuLi, THF, $0{ }^{\circ} \mathrm{C}$; (b) $\mathrm{Me}_{2} \mathrm{SiCl}_{2}$ (4 equiv), $0{ }^{\circ} \mathrm{C}$; (c) 1,3-dithiane, BuLi, $0{ }^{\circ} \mathrm{C}$; (d) $\mathrm{MeOH}$, $\mathrm{TsOH}$ (cat); (e) 5,9-dibromononene (1.2 equiv), LDA (2.4 equiv), THF, $-78^{\circ} \mathrm{C}$; (f) $\mathrm{CAN}$ (2.5 equiv), $\mathrm{NaHCO}_{3}(6$ equiv), $\mathrm{CH}_{3} \mathrm{CN}, \mathrm{CH}_{2} \mathrm{Cl}_{2}, \mathrm{H}_{2} \mathrm{O},-50^{\circ} \mathrm{C}$; (g) $\mathrm{Bu} 3 \mathrm{SnH}$ (1.2 equiv), AlBN (cat), $\mathrm{PhH}, 80^{\circ} \mathrm{C}$; (h) $\mathrm{Bu} 3 \mathrm{SnH}(1.2$ equiv), $\mathrm{Et}_{3} \mathrm{~B}$ /hexane (1.0 M, 2 equiv), dry air, $\mathrm{PhH}_{1} \mathrm{rt}$; (i) $\mathrm{H}_{2} \mathrm{O}_{2}$ (10 equiv), $\mathrm{KHCO}_{3}$ (3 equiv), $\mathrm{KF}$ (3 equiv), $\mathrm{MeOH}$, THF. 
underwent tandem cyclizations to generate cyclic silyl ethers. Oxidative hydrolysis of these silyl ethers resulted in a net transfer of the substituent from silicon of the acylsilanes to carbon.

Acknowledgments. Financial support by the National Science Council of the Republic of China is gratefully acknowledged.

\section{REFERENCES AND NOTES}

1. (a) Ricci, A.; Degl'Innocenti, A. Synthesis 1989, 647-660. (b) Page, P. C. B.; Klair, S. S.; Rosenthal, S. Chem. Soc. Rev. 1990, 19, 147-195. (c) Cirillo, P. F.; Panek, J. S. Org. Prep. Proc. Int. 1992, 24, 553-582.

2. (a) Tsai, Y.-M.; Cherng, C.-D. Tetrahedron Lett. 1991, 32, 3515-3518. (b) Curran, D. P.; Jiaang, W.T.; Palovich, M.; Tsai, Y.-M. Synlett 1993, 403-404. (c) Tsai, Y.-M.; Tang, K.-H; Jiaang, W.-T. Tetrahedron Lett. 1993, 34, 1303-1306. (d) Tsai, Y.-M.; Chang, S.-Y. J. Chem. Soc., Chem. Commun. 1995, 981-982.

3. (a) Dalton, J. C.; Borque, R. A. J. Am. Chem. Soc. 1981, 103, 699-700. (b) Harris, J. M.; MacInnes, I.; Walton, J. C.; Maillard, B. J. Organomet. Chem. 1991, 403, C25-C28. (c) Tsai, Y.-M.; Ke, B.-W. J. Chin. Chem. Soc. 1993, 40, 641-642. (d) Robertson, J.; Burrows, J. N. Tetrahedron Lett. 1994, 35, 3777-3780.

4. (a) Ho, T.-L.; Ho, H. C.; Wong, C. M. J. Chem. Soc., Chem. Commun. 1972, 791-791. (b) Cristau, H.-J.; Chabaud, B.; Labaudinière, R.; Christol, H. Synth. Commun. 1981, 11 , 423-428.

5. Stork, G.; Zhao, K. Tetrahedron Lett. 1989, 30, 287-290.

6. (a) Tamao, K.; Ishida, N.; Tanaka, T.; Kumada, M. Organometallics 1983, 2, 1694-1696. (b) Tamao, K.; Nakajima, T.; Sumiya, R.; Arai, H.; Higuchi, N.; Ito, Y. J. Am. Chem. Soc., 1986, 108, 6090-6093.

7. Canonne, P.; Foscolos, G. B.; Bélanger, D. J. Org. Chem. 1980, 45, 1828-1835.

8. Analyzed using a $3.3 \mathrm{~mm} \times 2 \mathrm{~m}$ column packed with $10 \%$ SE-30 on Chromosorb $\mathrm{W}$ under a flow rate of $30 \mathrm{~mL} / \mathrm{min}$. Retention time $(\mathrm{min})$ at column temperature $=130^{\circ} \mathrm{C}: \mathbf{7 a}=6.3, \mathbf{8 a}=7.1,9 \mathbf{a}=7.9$.

Retention time $(\mathrm{min})$ at column temperature $=140^{\circ} \mathrm{C}: \mathbf{7 b}=8.5, \mathbf{8 b}=9.4,9 \mathbf{b}=10.5, \mathbf{1 5}=11.6, \mathbf{1 8 a}=$ $7.8,19 \mathrm{a}=10.5,20 \mathrm{a}=9.4, \mathbf{1 8} \mathrm{b}=13.2, \mathbf{1 9} \mathrm{b}=16.0,21=16.9$.

9. (a) Wilt, J. W. J. Am. Chem. Soc., 1981, 103, 5251-5253. (b) Wilt, J. W. Tetrahedron 1985, 41, 3979. 4000. (c) Wilt, J. W.; Lusztyk, J.; Peeran, M.; Ingold, K. U. J. Am. Chem. Soc., 1988, 110, $281-287$. (d) Myers, A. G.; Gin, D. Y.; Rogers, D. H. J. Am. Chem. Soc., 1994, 116, 4697-4718.

10. Acylsilane $\mathbf{1 5}$ was synthesized using methods similar to the synthesis of $\mathbf{6 b}$ as shown in scheme II. Instead of 1,5-dibromopentane, 1-bromopentane was used.

11. We did not determine the exact olefin geometry of $\mathbf{2 5 a}$ and $\mathbf{2 5 b}$.

12. (a) Shono, T.; Nishiguchi, 1.; Ohmizu, H.; Mitani, M. J. Am. Chem. Soc., 1978, 100, 545-550. (b) Belotti, D.; Cossy, J.; Pete, J. P.; Portella, C. J. Org. Chem. 1986, 5I, 4196-4200.

13. 26: ${ }^{1} \mathrm{H}$ NMR (200 MHz, $\left.\mathrm{CDCl}_{3}\right) \delta 0.88\left(\mathrm{~d}, J=6.7 \mathrm{~Hz}, 3 \mathrm{H}\right.$, methyl), $0.98-2.20(\mathrm{~m}, 15 \mathrm{H}) \mathrm{ppm} ;{ }^{13} \mathrm{C}$ NMR $\left(50 \mathrm{MHz}_{2} \mathrm{CDCl}_{3}\right) \delta 12.7,23.2,25.0,27.8,29.6,31.1,33.7,36.2,47.1,81.0 \mathrm{ppm}$.

14. See also: (a) RajanBabu, T. V.; Fukunaga, T. J. Am. Chem. Soc., 1989, III, 296-300. (b) RajanBabu, T. V. Acc. Chem. Res. 1991, 24, 139-145.

15. (a) Nozaki, K.; Oshima, K.; Utimoto, K. J. Am. Chem. Soc., 1987, 109, 2547-2549. (b) Miura, K.; Ichinose, Y.; Nozaki, K.; Fugami, K.; Oshima, K.; Utimoto, K. Bull. Chem. Soc. Jpn. 1989, 62, $143-$ 147. (c) Clive, D. L. J.; Postema, M. H. D. J. Chem. Soc., Chem. Commun. 1993, 429-430. 